\title{
HEAT TREATMENT FOR AN RECYCLING ALUMINUM AA6061 USING MILLING PROCESS AT VARIOUS HOLDING AGING TIME
}

\author{
Ahmed Sahib Mahdi ${ }^{1,2}$, Mohd Sukri Mustapa ${ }^{3}$, Noradila Abdul Latif ${ }^{4}$, Muhammad Irfan Ab Kadir ${ }^{5}$, \\ Mohd Arif Samsi ${ }^{5}$ \\ 1,3,4,5 Faculty of Mechanical and Manufacturing Engineering, Universiti Tun Hussein Onn Malaysia (UTHM), \\ 86400 Parit Raja, Batu Pahat, Johor, Malaysia \\ ${ }^{2}$ Technical University, Iraq \\ ${ }^{1}$ ahmedaltaei@yahoo.com, ${ }^{3}$ sukri@uthm.edu.my \\ ${ }^{4}$ noradila@uthm.edu.my, ${ }^{5}$ irfankadir91@gmail.com, ${ }^{5}$ arif-samsi90@yahoo.com
}

\begin{abstract}
In this investigation, AA6061 milled particle size was fabricated by milling machine and later compacted by hydraulic press in room temperature. Seven specimens were chosen for the heat treatment process. For reference, one specimen was treated solely by the quenching and another one was treated by the aging only, On top of that, there were five specimens were subjected to various holding times during the aging. The experimental results show that the maximum value of compression strength was 300.47 MPa for the specimen subjected to quenching and aging of holding time 4 hours and the maximum value for microhardness was $\mathbf{1 0 0 . 4 4} \mathrm{Hv}$ for the same specimen. While the density value was decreased with increasing the holding time. The maximum value of the density was $2.61 \mathrm{~g} / \mathrm{cm}^{3}$ for the specimen (Quenching only). X-ray inspection was detected some of chemical compound were created such as (Al86Fe14) and (Cr13Ni5Si2).
\end{abstract}

Keyword- Aging process, Milling process, Powder metallurgy, Recycling aluminium, AA6061.

\section{INTRODUCTION}

6xxx Al-Mg-Si alloys have been widely used in automotive body panels as main substitute materials for weight reduction [1]. The industry has been focused on the materials as recycling, specifically the materials have been used more and more costly. These recycling offers several advantages which include their relatively lower production costs, isotropic properties and the possibility of using conventional shaping methods (e.g. Extrusion, forging, and rolling) for component manufacturing [2]. Among the various physical and chemical methods, a mechanical ball-mill technique is recognized as a simple and cost-effective method to produce fine and homogeneous powders [3]. During the past 20 years, high energy ball milling has extensively been utilized as a versatile method to produce a variety of advanced compound powders. The main difference between high energy milling by the planetary ball mill, Spex, Attritor mill, etc. and conventional milling is that the former applies much larger doses of energy to particles over time [4]. This large input energy makes high energy mills capable of producing materials with special properties that could not be synthesized by other methods. The milling process produces considerable strain hardening in the Al powder, which is directly reflected on the final properties of the composite powders, therefore, it is needed to treat with heat treatment process [5]. A commercial AA6061 aluminum alloy is one of the $\mathrm{Al}, \mathrm{Mg}, \mathrm{Si}(\mathrm{Cu})$ system alloys that can be significantly hardened by a proper heat treatment. Because of its medium strength, excellent corrosion resistance, and weldability, the AA6061 alloy has been widely used as structural material for construction, transportation and sports [6]. (Lipeng et.al.2015) has been treated aluminium AA6022 by various aging temperature $(80,100,130$ and $\left.170{ }^{\circ} \mathrm{C}\right)$ and various holding times $(2,3,4 \mathrm{hrs})$. He has concluded that the $100^{\circ} \mathrm{C}$ by $3 \mathrm{hrs}$ is the best attempt. Other than that, there were researchers had been published some other research related to this field $[9,10,11]$.

In this study, the heat treatment has an effect on the mechanical properties of AA6061. The object of this study is the selection of the optimal process of the heat treatment which has been given the best mechanical properties. Otherwise, The holding time of aging process affected to density, hardness and compression strength. Therefore, these mechanical properties are the basic characteristics of composites produced by powder metallurgy technique. On the other hand, the significance of this study is reuse the aluminum scrap such as the chip returned from turning or the semi finished product. This research helps to save the cost of the aluminum manufacturing and the protection of the environment against pollution. 


\section{EXPERIMENTAL WORK}

\section{A. Material}

AA6061 is a relatively light metal compared to other metals such as steel, nickel, brass and copper with a specific gravity of $2.7 \mathrm{~g} / \mathrm{cm}^{3}$, the Chemical Composition for Aluminium AA6061 is shown in Table I. Zinc stearate was used as a binder to make the compaction process easier [13].

TABLE I chemical composition of aluminium aa6061 (ASTM b308/b308m)

\begin{tabular}{|l|l|}
\hline Element & Percentage \% \\
\hline $\mathrm{Si}$ & 0.59 \\
\hline $\mathrm{Fe}$ & 0.092 \\
\hline $\mathrm{Cu}$ & 0.289 \\
\hline $\mathrm{Mn}$ & 0.08 \\
\hline $\mathrm{Mg}$ & 0.975 \\
\hline $\mathrm{Cr}$ & 0.2 \\
\hline $\mathrm{Zn}$ & 0.031 \\
\hline $\mathrm{Ni}$ & 0.1 \\
\hline $\mathrm{Al}$ & Rem \\
\hline
\end{tabular}

\section{B. Chip production}

Firstly, the chips were as produced by using CNC milling machine, type HSM (SODICK - MC4301), Feed rate $(1100 \mathrm{~mm} / \mathrm{min})$, Depth of cut $(1.0 \mathrm{~mm})$ and cutting velocity $(345.4 \mathrm{~m} / \mathrm{min})$ [12].

\section{Chip cleaning and drying}

Milled aluminium particles were cleaned by ultrasonic bath apparatus, type Fritsch (ultrasonic cleaner labarette 17). The duration was 1 hour for each patch. After that, it was treated with acetone solution for $20 \mathrm{~min}$. Finally, the drying process was used (Kuittho Linn High Therm type of furnace) for 1 hour [14].

\section{Milling process}

The chip was milled by planetary ball mill type (Retsch PM100) under conditions of the speed 350 RPM for $20 \mathrm{hrs}$. The ratio of ball to powder (RBP) was 20:1 [15].

\section{E. Mixing and compaction}

The ball mill machine was used for mixing the powders for the duration of $1 \mathrm{hr}$ at the speed of 300 RPM to make sure that the distribution was completed. The composition of mixture to produce the samples between the AA6061 and Zinc stearate was equal along the size that equal to $99 \%$ of AA6061 and 1\% of zinc stearate.

Cold compaction of powder blends was performed in this study. Cold compaction was performed at room temperature (RT). In cold compaction, the mixed powder with a given amount of lubricant was pressed by uniaxial hydraulic operated press, The die was supported by two circular blocks of steel to allow uniform movement of the die during compaction, The cleaned surfaces of die wall and tools (upper and lower punch) were sprayed with a lubricant-saturated solution

\section{F. Sintering process}

Sintering process is to provide extra bonding between atoms. The atomic diffusion takes place and welded areas created during the compaction will increase bonding by this process. The controlled parameters during the sintering were heating rate time; temperature and atmosphere, all are necessary to obtain a consistent results.

The equipment used during the sintering process was tube furnace [16], the inert gas used during the process was Argon gas. The sintering temperature was used as mentioned in eq. 1

$$
\text { Sintering Temperature }=(0.7-0.9) \mathrm{Tm}
$$

Hence: $\mathrm{Tm}=$ melting point

\section{Physical property inspection}

Density, microhardness and compression strength were investigated in this study. Density $\left(D_{B}\right)$ and dense, usually refer to a measure how much of some entities are within a fixed amount of space. Then, the mass of many particles of a particulate solid or a powder, divided by the total volume they occupied is called Bulk density. 


\section{G. Heat treatment process}

Heat treatment of aluminium is a heat-treating process whereby the aluminium is exposed to an elevated temperature for a period of time and cooled off, which transforms or changes the mechanical properties without changing the specimen shape. The heat treatment can be defined as an operation or set of operations in a metal involving heating and controlled cooling. Transformation in the solid state can be obtained using heat treatment procedures, which cause changes in microstructure resulting in materials with a wide range of hardness and mechanical properties [11]. Although an exact relationship between hardness and wear behavior does not exist, hardness has traditionally been the properly used for quality control, and heat treatment and performance evaluation.

Two processes were performed in this step (quenching \& artificial aging). The quenching process was performed at $530^{\circ} \mathrm{C}$ for $2 \mathrm{hrs}$, after that quenched by water to room temperature $\left(\approx 25^{\circ} \mathrm{C}\right)$. Subsequently, the aging process was carried out at $175^{\circ} \mathrm{C}$ for various of time $(2,4,6,8,10) \mathrm{hrs}$, after that cooled by air to room temperature. Fig. 1 shows the profile of the quenching and the aging process. Table II shows the classification of specimens.

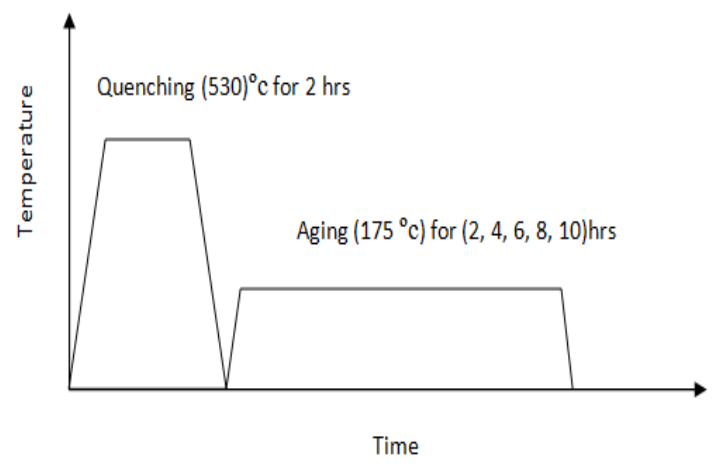

Fig.1 the profile of heat treatment process

TABLE II The classification of specimens

\begin{tabular}{|c|l|}
\hline Specimen symbol & Description \\
\hline $\mathrm{J}_{\mathrm{Q}}$ & Quenching only at $\left(530^{\circ}\right)$ for $(2 \mathrm{hrs})$ \\
\hline $\mathrm{J}_{\mathrm{QA} 1}$ & Quenching $\left(530^{\circ}\right)$ for $(2 \mathrm{hrs})+$ Aging $\left(175^{\circ}\right)$ for $(2 \mathrm{hrs})$ \\
\hline $\mathrm{J}_{\mathrm{QA} 2}$ & Quenching $\left(530^{\circ}\right)$ for $(2 \mathrm{hrs})+$ Aging $\left(175^{\circ}\right)$ for $(4 \mathrm{hrs})$ \\
\hline $\mathrm{J}_{\mathrm{QA} 3}$ & Quenching $\left(530^{\circ}\right)$ for $(2 \mathrm{hrs})+$ Aging $\left(175^{\circ}\right)$ for $(6 \mathrm{hrs})$ \\
\hline $\mathrm{J}_{\mathrm{QA4}}$ & Quenching $\left(530^{\circ}\right)$ for $(2 \mathrm{hrs})+$ Aging $\left(175^{\circ}\right)$ for $(8 \mathrm{hrs})$ \\
\hline $\mathrm{J}_{\mathrm{QA} 5}$ & Quenching $\left(530^{\circ}\right)$ for $(2 \mathrm{hrs})+$ Aging $\left(175^{\circ}\right)$ for $(10 \mathrm{hrs})$ \\
\hline $\mathrm{J}_{\mathrm{A}}$ & Aging only (in optimum aging time $)$ \\
\hline
\end{tabular}

III.RESULTS AND DISCUSSION

The manufactured parts by powder metallurgy have been getting lower bonding force between the particles compare with the traditional method of the melting of metals, at the same time, many of the advantages have been getting by using powder metallurgy. Therefore, the heat treatment process was improved the bonding between the particles and was increased the desirable mechanical properties. Therefore, some physical and mechanical properties of the prepared material were studied. Density, microhardness and compression strength were selected for this study.

The application of the term heat treatable to aluminium alloys is limited to the specific operations used to increase strength and hardness by precipitation hardening thus the term heat treatable used to distinguish the heat treatable alloys from those alloys in which no significant strength improvement can be achieved by heating and cooling.

Heat treatment process was applied to the prepared material and involves a heat treatment whereby the alloying constituents are taken into solution and retained by rapid quenching. Subsequent, artificial aging was performed at lower temperatures. The aging process was allowed for a controlled precipitation of the constituents, thereby achieving increased hardness and strength. 
Seven specimens were chosen for this step of the test. Fig.2 shows the relation between compression strength and the type of specimen.

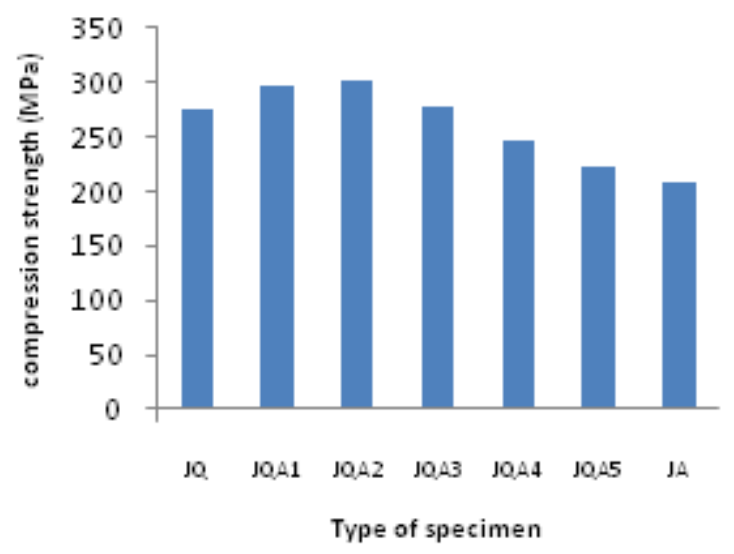

Fig.2 The relation between compression strength and the type of specimen.

It can be seen that the specimen type $\mathrm{J}_{\mathrm{QA} 2}$ has the highest value for compression strength (300.47 MPa) compared with the others. So, the strength was slightly enhanced with the increasing of the aging time until $4 \mathrm{hrs}$ as indicated by the specimen $\mathrm{J}_{\mathrm{QA2}}$. Consequently, when the aging holding time increased, the compression strength value decreased. The improvement ratio for the specimen $\mathrm{J}_{\mathrm{QA} 2}$ was taken $53 \%$ compares with the specimen (as fabricated). These changes of values attributed to the amount of the created compound by the heat treatment process. $\mathrm{Al}_{86} \mathrm{Fe}_{14}$ and $\mathrm{Cr}_{13} \mathrm{Ni}_{5} \mathrm{Si}_{2}$ were found as created compound. Fig. 3 shows the created compound by $x$-ray inspection. Improvement value of compression strength was applicable for the specimen $\mathrm{J}_{\mathrm{Q}}$, it was $41 \%$ of as fabricated specimen, which was $276.47 \mathrm{MPa}$. The aging process caused the pore volume fraction was reduced by the compound created. So, it was as a barrier between the particles. The largest content of the compound was found at the specimen $\mathrm{J}_{\mathrm{QA2}}$. Therefore, the compression strength was improved. When the amount of created compound decreased, the compression strength decreased due to the precipitation of the created compound was less amount. Table III shows the value of compression strength and the improvement ratio of each heat treated specimens.

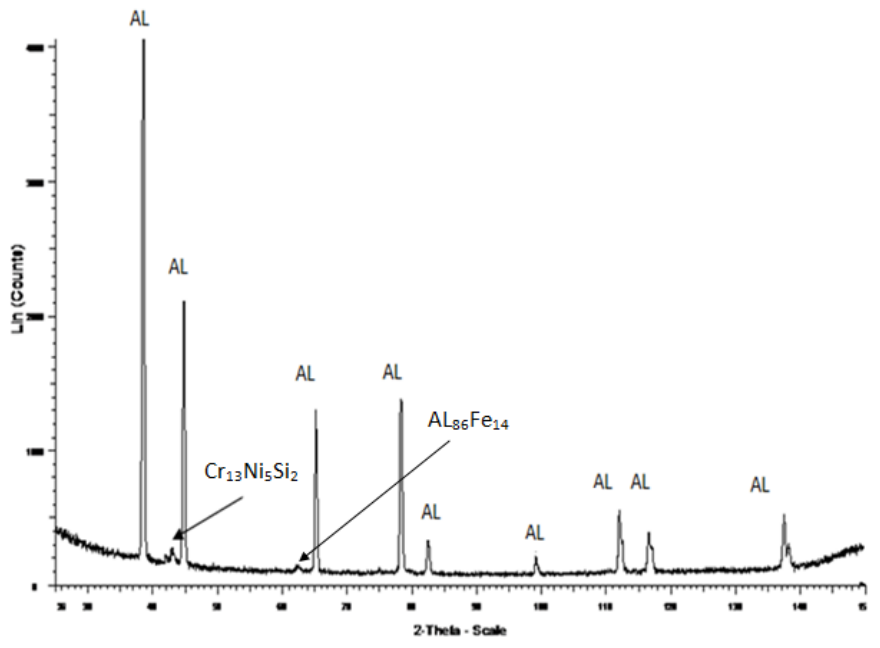

Fig. 3 the created compound by $\mathrm{x}$-ray inspection 
TABLE III the value of compression strength and the improvement ratio

\begin{tabular}{|c|c|c|}
\hline Specimen symbol & Compression strength $\mathrm{MPa}$ & Improvement ratio \% \\
\hline $\mathrm{J}_{\mathrm{Q}}$ & 276.47 & 41 \\
\hline $\mathrm{J}_{\mathrm{QA} 1}$ & 297.84 & 52 \\
\hline $\mathrm{J}_{\mathrm{QA} 2}$ & 300.47 & 53 \\
\hline $\mathrm{J}_{\mathrm{QA} 3}$ & 277.5 & 41 \\
\hline $\mathrm{J}_{\mathrm{QA} 4}$ & 246.76 & 26 \\
\hline $\mathrm{J}_{\mathrm{QA} 5}$ & 221.78 & 13 \\
\hline $\mathrm{J}_{\mathrm{A}}$ & 209.31 & 7 \\
\hline
\end{tabular}

These seven specimens were subjected to Microhardness test. Fig.4 shows the relation between the Microhardness value and the types of specimens. It can be seen that the microhardness value increased with the increasing of aging time and reached its peak at the specimen type $\mathrm{J}_{\mathrm{QA} 2}$, subsequently, the value was steadily falling until the specimen $\mathrm{J}_{\mathrm{A}}$ due to the decreasing of the created compound was happening.

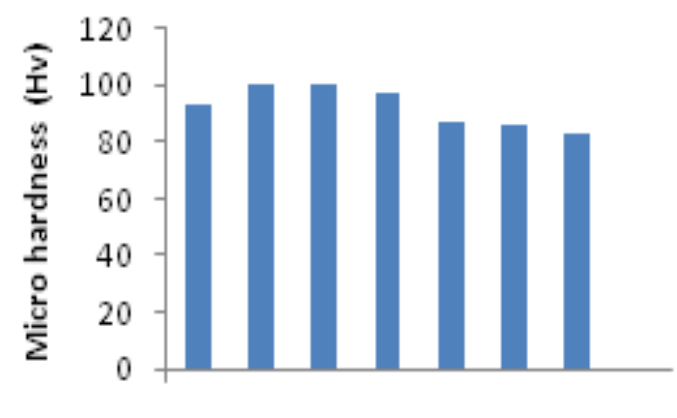

JQ. JOA1 JOA2 JOA3 JOA4 JOAS JA

\section{Type of specimen}

Fig.4 The hardness values for various specimens

Heat treatment process was effected on the density values for the specimens. The above seven specimens were subjected to the density test. Fig. 5 shows the relation between the density value and the types of specimens.

The specimen $\mathrm{J}_{\mathrm{QA} 2}$ (quenching and aging) has the biggest density value $2.61 \mathrm{~g} / \mathrm{cm}^{3}$. So, when the aging time increased, the density value decreased due to the amount of the created compound was decreased between particles according to X-ray results. The particles were saturated by the created compound during the quenching process, then the aging process was affected by the amount of the compound. When the aging time increased, the compound increased with aging time $4 \mathrm{hrs}$, after that decreased. The precipitation amount was caused to increase the density. The created compound was driven out by the aging time, as well as, the increasing of aging time after aging time $4 \mathrm{hrs}$ were led to decreasing of the amount of created compound. On the other hand, the increasing of the amount of created compound leads to increasing of density.

By the three tests mentioned above, the specimen $\mathrm{J}_{\mathrm{QA} 2}$ has the highest values for both microhardness and compression strength.

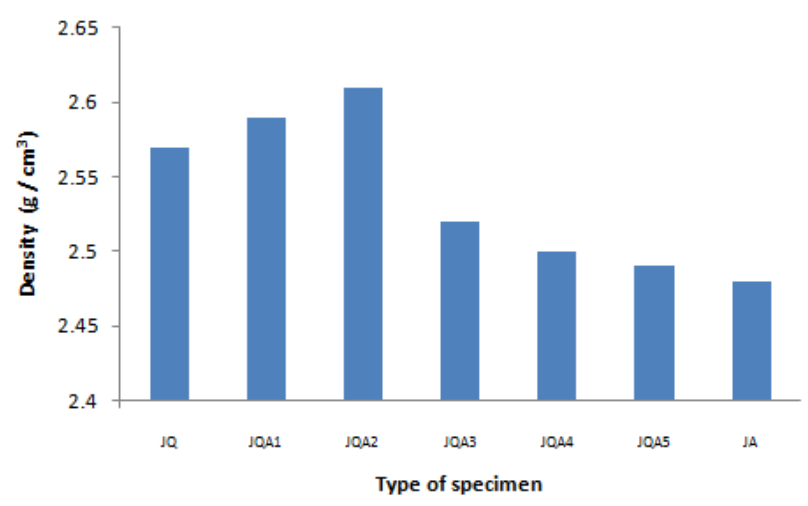

Fig.5 The relationship between the density value and the types of specimens 


\section{IV.CONCLUSIONS}

According to the experimental results, it is revealed that the heat treatment process were successfully conducted. So, it can be concluded the effect of aging time on the density, microhardness and compression strength. When the aging time increased, the mechanical properties increased. The maximum value was obtained at the aging time of $4 \mathrm{hrs}$ due to the created compound caused that the pores between the particles were reduced. After that, the mechanical properties showed a decrease trend after the $4 \mathrm{hrs}$ aging time. The maximum value of compression strength was $300.47 \mathrm{MPa}$, while the maximum value of the microhardness was $100.44 \mathrm{Hv}$.

On the other hand, high density value was given by the specimen quenching and aging by aging time $4 \mathrm{hrs,}$ which was $\left(2.61 \mathrm{~g} / \mathrm{cm}^{3}\right)$. In contrast, the others had given a lower value of the density. The results were attributed to creating the chemical compound $\mathrm{Al}_{86} \mathrm{Fe}_{14}$ and $\mathrm{Cr}_{13} \mathrm{Ni}_{5} \mathrm{Si}_{2}$ between the particles. So, when the aging time increased to $4 \mathrm{hrs}$, then the created compound increased, therefore the density increased, but the density was decreased after 4 hours due to the created compound decreased.

\section{FUTURE SCOPE}

AA6061 is an important metal in the industry. Many of parts were fabricated by it in many applications. The recycling of the material will save more cost and metal. Therefore, the other powder fabrication processes are also important to be studied. On the other hand, the heat treatment process is the significant process to develop the mechanical properties. The quenching temperature and quenching holding time are important to be investigated.

\section{ACKNOWLEDGMENT}

The authors would like to thank to University Tun Hussein Onn Malaysia (UTHM) for sponsoring this work and short term Grant No. U 358.

\section{REFERENCES}

[1] Kwang-Jin LEE, Eui-Pyo KWON "Microstructure of stir zone in dissimilar friction stir welds of AA6061-T6 and AZ31 alloy sheets" science direct, Trans. Nonferrous Met. Soc. China 24(2014) 2374-2379.

[2] A. Santos-Beltrán, R. Goytia-Reyes, H. Morales-Rodriguez, V. Gallegos-Orozco, M. Santos-Beltrán, F. Baldenebro-Lopez, R.Martínez-Sánchez "Characterization of Al-Al4C3 nanocomposites produced by mechanical milling" Materials Characterization, Materials Characterization 106 (2015) 368-374.

[3] Sung-Mo Hong, Jin-Ju Park, Eun-Kwang Park, Kyeong-Youl Kim, Jung-Gu Lee, Min-Ku Lee, Chang-Kyu Rhee, Jin Kyu Lee "Fabrication of titanium carbide nano-powders by a very high speed planetary ball milling with a help of process control agents" Powder Technology, 274 (2015) 393-401.

[4] S.S. Razavi-Tousi and J.A. Szpunar "Effect of Ball Size on Steady State of Aluminum Powder and Efficiency of Impacts during Milling" Powder Technology, June (2015).

[5] M. Raviathul Basariya, V.C. Srivastava, N.K. Mukhopadhyay "Microstructural characteristics and mechanical properties of carbon nanotube reinforced aluminum alloy composites produced by ball milling" Materials and Design 64 (2014) 542-549.

[6] Cheng-Yu Chou, Che-Wei Hsu, Sheng-Long Lee, Kuan-Wen Wang, Jing-Chie Lin" Effects of heat treatments on AA6061 aluminum alloy deformed by cross-channel extrusion" journal of materials processing technology $202\left(\begin{array}{llll}2 & 0 & 0 & 8\end{array}\right)$ 1-6.

[7] Md. ShahnewazBhuiyan, HiroyukiToda, ZhangPeng, SuHang, KeitaroHorikawa, KentaroUesugi, AkihisaTakeuchi, NobutoSakaguchi, YoshioWatanabe" Combined microtomography, thermal desorption spectroscopy, X-ray diffraction study of hydrogen trapping behavior in 7XXX aluminum alloys" Materials Science\&Engineering, A655(2016)221-228.

[8] Lipeng Ding, Yang He , Zhang Wen, Pizhi Zhao, Zhihong Jia, Qing Liu "Optimization of the pre-aging treatment for an AA6022 alloy at various temperatures and holding times" Journal of Alloys and Compounds 647 (2015) 238-244.

[9] Huda Mohammed, Nasser Malik Abbas, Amjad Hussain Jasim “ zRTIFITIAL AGING TIME EFFECT ON CORROSION RESISTANCE FOR FRICTION STIR WELDED AA6061 T6" Diyala Journal of Engineering Sciences, Vol. 06, No. 03, pp. 83-96, September 2013.

[10] Malik Niama Hawas "Effect of Ageing Time on Adhesive Wear of AL Alloy AA6061-T6" Journal of Kerbala University , Vol. 11 No.4 Scientific. 2013.

[11] Evren TAN and Bilgehan "OGEL "Influence of Heat Treatment on the Mechanical Properties of AA6066 Alloy" Turkish J. Eng. Env. Sci., 31 (2007), $53-60$.

[12] A. S. Mahdi, M. S.Mustapa, M. A. Lajis, M. W .A. Rashid " Effect of Compaction Pressure on Physical Properties of Milled aluminium Chip (AA6061)" International Journal of Science and Research, Volume 4 Issue 9, September 2015

[13] A. S. Mahdi, M. S.Mustapa, M. A. Lajis, M. W .A. Rashid "Compression Strength and Microhardness of Recycling Milled Aluminium (AA6061) for Various Binder" International Journal of Mechanical and Industrial Technology, Vol. 3, Issue 2, pp: (98-104), Month: October 2015 - March 2016.

[14] A. S. Mahdi, M. S.Mustapa, M. A. Lajis, M. W .A. Rashid "effect of holding time on mechanical properties of recycling aluminium alloy AA6061 through ball mill process" International Journal of Mechanical Engineering and Technology (IJMET), Volume 6, Issue 9, Sep 2015, pp. 133-142.

[15] A. S. Mahdi, M. S.Mustapa, M. A. Lajis, M. W .A. Rashid "Study Of Physical Properties Of Recycling Aluminium Chip (AA6061) On Holding Time Through Milling Process," International journal of modern engineering research (IJMER), Vol. 5, Iss. 11, November 2015 (47).

[16] A. S. Mahdi, M. S.Mustapa, M. A. Lajis, M. W .A. Rashid "Physical Properties of Recycling Milled Aluminium Chip (AA6061) for Various Sintering Temperature" International Journal of Mechanical sand Industrial Technology, Vol. 3, Issue 2, pp: (33-40), Month: October 2015 - March 2016. 